\title{
REDE DE INTERAÇÃO FEIJÃO MANGALÔ (Dolichos lablab) E SEUS
}

\author{
VISITANTES FLORAIS
}

\section{$\underline{\text { Bianca Dorea Santos }{ }^{1} \text {,Gilberto Marcos Mendoca Santos }}{ }^{2}$}

1. Bolsista PROBIC/UEFS, Graduando em Agronomia, Universidade Estadual de Feira de Santana, e-mail: biiadorea5@outlook.com

2. DCBIO, Universidade Estadual de Feira de Santana, e-mail: gmms.uefs@gmail.com

PALAVRAS-CHAVE: visitantes florais; feijão; interação

\section{Introdução}

Os estudos sobre redes de interação animal-planta têm sido de grande relevância para o entendimento da estrutura, dinâmica e outros processos ecológicos em comunidades (MEMMOTT, 1999). Apesar de seus fundamentos terem sido estabelecidos e consolidados anteriormente, em diversas áreas do saber (JORDANO, 1987; STROGATZ, 2001), o uso de redes na ecologia é relativamente novo. E esse olhar sobre redes possibilitou o entendimento de uma variedade de fenômenos e mecanismos causais que moldam e estruturam comunidades ecológicas (PAINE,1980; POLIS, 1999; BORER et al, 2005).

Diferentes grupos de insetos apresentam diferentes eficácias na polinização, sendo que, esses grupos apresentam diferentes padrões temporais de visita. O fato é que, estudos vêm apontando um declínio no número de polinizadores em todo o mundo (BIESJEIMER et al., 2006; MARTINS \& MELO, 2010). Sendo assim, estudar como os visitantes florais interagem em suas coletas de recursos são imprescindíveis para uma melhor compreensão do funcionamento do ecossistema e de como diferentes estratégias de forrageamento são utilizadas, a fim de evitar a competição interespecífica e permitir a coexistência entre eles, a exemplo das abelhas (CARVALHO, 2009). O estudo das interações inseto-planta nas redes tróficas é apontado como básico para melhorar nosso conhecimento sobre esta questão (DEL-CLARO \& TOREZAN-SILINGARDI, 2009). Sendo que, a identificação dos horários preferenciais dos polinizadores, podem ser utilizados para criação de novas estratégias de manejo. Por exemplo, realizar a irrigação 
e/ou aplicação de defensivos agrícolas em diferentes horários dos usados pelos polinizadores.

As plantas que dependem dos visitantes florais para a realização da polinização têm controle limitado sobre o deslocamento polínico devido à presença de muitos fatores, tais como a densidade e a presença de outras espécies floridas (STEPHENSON \& BERTIN, 1983). A oferta de alimento no ambiente é de fundamental relevância para os visitantes florais. Uma planta só deverá ser forrageada pelo seu polinizador se o tempo gasto em viagem e extração dos recursos florais for menor que o tempo que ele gastaria se fosse forragear outras espécies de plantas no mesmo habitat (PATON, 1997). Mas, para isso, faz-se necessário condições adequadas de voo para a atividade de forrageamento (SILVEIRA et al, 2002; TEIXEIRA \& CAMPUS, 2005). O horário de forrageio, por exemplo, pode ser influenciado pela quantidade de recurso floral disponível (CARVALHO, 2009), e também pela temperatura (IMPERATRIZ FONSECA et al, 1985) levando a uma redundância na comunidade de visitantes florais.

\section{Materiais e Métodos}

O presente trabalho foi desenvolvido na Estação Experimental de Horticultura da Universidade Estadual de Feira de Santana, município de Feira de Santana - BA. A espécie floral do presente estudo é Dolichos lablab, uma Fabaceae com grande potencial econômico, foi realizada a implantação dessa cultura na Estação Experimental

,durante os 5 primeiros meses do seu desenvolvimento, foram realizados tratos culturais na espécie até o seu florescimento . Após o florescimento inicia-se o registro de cada interação inseto-planta sendo analisado como uma unidade amostral. Registramos as flores visitadas, tempo de visita, temperatura, umidade relativa do ar e luminosidade, de hora em hora durante cada amostragem, espécies visitadas e número de flores vizinhas a flor visitada. Durante as amostragens, dois coletores capturaram os insetos que visitam as flores, usando redes entomológicas utilizando da técnica de varredura, ao longo da mesma linha traçada no terreno de $1 \mathrm{~km}(20 \mathrm{~m})$ de comprimento. O esforço de amostragem por planta em flor é de 15 min. Realizamos amostragem das 06:00 às 18:00 
horas com vistas semanais. Os indivíduos coletados serão quantificado e devidamente identificado por especialistas. Dessa forma buscar a confirmação da hipótese de que 
horário da disponibilidade dos recursos florais influencia no padrão de atividade diária dos visitantes florais.

\section{Resultados e/ou Discussão}

A rede de interações estabelecidas na área de estudo foi composta por sete espécies, até o presente momento não identificadas. Foi determinante a observação das condições abióticas, que exerceram intensa influência, nos resultados encontrados referentes a visitações. A abundância de visitantes florais acompanhou a variação dos fatores abióticos ao longo do dia, foi observado uma intensa atividade no período de 9:0o pm e 16:am, as abelhas pequenas preferem altas luminosidades e temperaturas para forragear, enquanto abelhas grandes, ao contrário, são mais tolerantes às variações de temperatura e forrageiam praticamente durante todo o dia. A moderada atividade no período da manhã pode está associada a baixa temperatura e alta umidade registrados intervalo, e no período da tarde, pode está veiculado a baixa temperatura associada a luminosidade. Baixas temperaturas, vento e baixa insolação podem diminuir a capacidade de vôo das abelhas (Burril \& Dietz 1981, Morato \& Campos 2000), principalmente das solitárias, que possuem baixa capacidade termorregulatória (Eickwort \& Ginsenberg 1980, Morato \& Campos 2000). As características corporais e limitações fisiológicas dos visitantes florais podem gerar padrões de visitação por dependência de fatores como luminosidade e temperatura (Ramalho et al. 1991). Além das restrições fisiológicas, esses padrões de visitação também podem ser moldados pela competição (Roubik 1978, Pyke 1984)

\section{Considerações Finais}

O estudo da interação inseto-planta se torna importantíssimo, para compreender que as plantas que dependem dos visitantes florais para a realização da polinização, possuem controle limitado sobre o deslocamento polínico devido a presença de muitos fatores, tais como a densidade e a presença de outras espécies floridas. A oferta de alimento no 
ambiente é de fundamental relevância para os visitantes florais. Uma planta só deverá ser forrageada pelo seu polinizador se o tempo gasto em viagem e extração dos recursos florais for menor que o tempo que ele gastaria se fosse forragear outras espécies de plantas no mesmo habitat. Mas para que isso ocorra faz-se necessárias condições de voo 
para atividade de forrageamento. Dentre essas condições encontramos a disponibilidade de recursos florais, as condições ambientais favoráveis (temperatura, umidade , luminosidade ) que atuam simultaneamente nos processos temporais das plantas e consequentemente no período de atividade dos visitantes florais .

\section{Referências}

CARVALHO, A.M.C. (2009) Guilda de abelhas e outros visitantes de Matayba guianensis (Sapindaceae) em vegetação de cerrado. Tese de Doutorado, Universidade Federal de Uberlândia.

FERREIRA, CARLO MAGRI. Feijão na economia nacional / Carlos Magri Ferreira, Maria José Del Peloso, Luís Cláudio de Faria. - Santo Antônio de Goiás: Embrapa Arroz e Feijão, 2002.

SANTOS, C. F. O. Morfologia dos nectários e concentração dos néctares de algumas plantas apícolas. ANAIS DA ESCOLA SUPERIOR DE AGRICULTURA LUIZ DE QUEIROZ, 1956, Piracicaba. Anais. Piracicaba: ESALQ, 1956, v.12, p 129- 146

SILVEIRA, F. A., MELO, G. A. R. \& ALMEIDA, E. A. B. 2002. Abelhas brasileiras: sistemática e identificação. Ministério do Meio Ambiente, Probio PNUD, Fundação Araucária, Belo Horizonte. 253 pp.

P.J. GULLAN, P. S. CRANSTON. Os insetos: um resumo de entomologia, São Paulo 2004 ed. 3. 229p SIEGEI., S. 1977. Estatística não paramétrica (para as Ciências do Comportamento). Rio de Janeiro, Editora McGraw Hill Ltda, 350p

Heinrich, B. 1974. Thermoregulation in endothermic insects. Science 185: 747-756.

Ramalho, M., V.L. Imperatriz-Fonseca \& A. KleinertGiovannini. 1991. Ecologia Nutricional de Abelhas Sociais p. 225-252. In A.R. Panizzi. \& J.R.P. Parra, Ecologia 
nutricional de insetos e suas implicações no manejo de pragas. CNPq, Ed. Manole Ltda., $359 \mathrm{p}$.

Burril, M. \& A. Dietz. 1981. The response of honeybees to variation in solar radiation and temperature. Apidologie 12: 319-328.

Morato, E.F. \& L.A.O. Campos. 2000. Partição de recursos florais de espécies de Sida linnaeus e Mauvastrum coromandelianum (Linnaeus) Garck (Malvaceae) entre Cephalurgus anomalus Moure \& Oliveira (Hymenoptera, Andrenidae, Panurginae) e Melissoptila cnecomala (Moure) (Hymenoptera, Apidae, Eucerini). Rev. Bras. de Zool. 17: 705-727.

Eickwort, G.C. \& H.S. Ginsberg. 1980. Foraging and mating behavior in Apoidea. Ann. Rev. Entomol. 25: 421-446

Roubik, D.W. 1978. Competitive interactions between neotropical pollinators and africanized honeybees. Science 201: 1030-1032 